\title{
Harmonic Elimination In Three Phase PWM Inverter By THIPWM
}

\author{
Vidit Sharma ${ }^{1}$, Ranvir Kaur ${ }^{2}$, Gursewak Singh Brar $^{3}$ \\ MTech.(Power System), BBSBEC, Fatehgarh ${ }^{1}$ \\ Assistant Professor, Electrical Engg. Deptt.., BBSBEC, Fatehgarh Sahib ${ }^{2}$ \\ Professor and Head, Electrical Engg. Deptt.., BBSBEC, Fatehgarh Sahib ${ }^{2}$ \\ Email:Vidit194@gmail.com ${ }^{1}$, ranvir7674@yahoo.co.in ${ }^{2}$, gursewak.singh@bbsbec.ac.in ${ }^{3}$
}

\begin{abstract}
This paper present internal control method, i.e. SPWM technique for the IGBT based inverter that can rely on a smaller harmonic with smoother voltage, but on the other hand it has more components and is more complex to control. Mainly inverter converts $\mathrm{AC}$ to $\mathrm{DC}$ power at a required voltage\& frequency. It also minimizes the harmonic distortion at the inverter output. Analysis and design are done by Simulink software to verifying results.
\end{abstract}

Keywords-MATLAB, $3^{\mathrm{RD}}$ Harmonic SPWM,IGBT.

\section{INTRODUCTION}

Three phase inverter is mainly used to convert AC power to DC power at desired voltage and frequency [1]. In this, we use the force commutated technique to provide an independent pulse to switch off any power device .we can use "IGBT" because of supporting bipolar voltage, high switching frequency, fully controlled switch (during turn-on and turn-off) and voltage range up to $1200 \mathrm{~V}, 300 \mathrm{~A}$ respectively. In this type, we have to maintain the gain of the inverter at a constant value which can use by various techniques i.e. 1. Variable frequency method. [2]

\section{PULSE WIDTH MODULATION}

Variable frequency method: In the variable frequency method, the chopping frequency has to be varied over a wide range for the control of output voltage so the filter is designed for such wide frequency variation, therefore, it's quite difficult for the control of alpha. So there is a possibility of interference with signalling and telephone line. In these type limitations, we can't use this type of method.

Pulse Width Modulation: This type of method is simpler and better than variable frequency method. But in this case, Ton cannot be reduced to zero for the commutation circuit used in the chopper:

\section{3. $3^{\text {RD }}$ HARMONIC INJECTION PULSE WIDTH MODULATION}

SPWM technique is easy to understand, but it does not fully utilized the DC supply voltage, $3^{\text {rd }}$ harmonic Injection Pulse Width Modulation technique is used. The idea of $3^{\text {rd }}$ harmonic injection is based on the fact that of a 3phase inverter bridge feeding a 3 phase AC load does not provide a zero sequence component of load current. In the case of delta connected load, there is no confusion, but in the case of star connected load three phases are connected and neutral point is floating for a balanced load. The floating neutral point has the advantage that there is no zero sequence component. In this technique, a suitable amount of third harmonic signal is added to the sinusoidal modulating signal of fundamental frequency. Now the resultant waveform is high frequency triangular carrier waveform. The carrier frequency waveform is higher tahan the modulating frequency signal. The compositon of pole voltage is same as the fundamental and third harmonic as in the modifying signal. The advantage of adding small amount of third harmonic in the modulating waveform is that it bring, down the peak magnitude of the resultant modulating waveform. The modifying modulating waveform is more flat topped than its fundamental component.

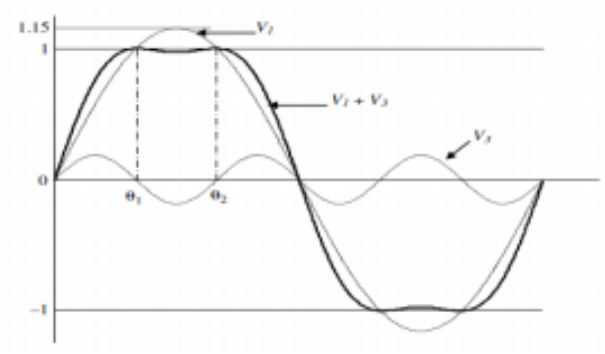

Figure 1:

In shown in the figure, if we assume the signal frequency of $2 \pi$ then the value of reference signal have two maixma at $t=$ $\pi / 3$ and $2 \pi / 3$ which is equal to 1 . The reference signal consist of fundamental and third harmonic frequency component has their following equation given below: 


\section{Available online at www.ijrat.org}

$$
\begin{aligned}
& \mathrm{V}_{\mathrm{a}}=\mathrm{V}_{(1 \max )} \operatorname{Sin}(\omega \mathrm{t})+\mathrm{V}_{(3 \max )} \sin (3 \omega \mathrm{t}) \\
& \mathrm{V}_{\mathrm{b}}=\mathrm{V}_{(1 \max )} \operatorname{Sin}(\omega \mathrm{t}-2 \pi / 3)+\mathrm{V}_{(3 \max )} \sin (3 \omega \mathrm{t} \\
& \mathrm{V}_{\mathrm{c}}=\mathrm{V}_{(1 \max )} \operatorname{Sin}(\omega \mathrm{t}+2 \pi / 3)+\mathrm{V}_{(3 \max )} \sin (3 \omega \mathrm{t})
\end{aligned}
$$

\section{INVERTER}

Power inverters are devices which can convert DC power into that of AC. Inverters can be broadly classified into two types based on their operation:

1. Voltage Source Inverters (VSI)[5]

2. Current Source Inverters (CSI)

A current source inverter is fed with adjustable current from a DC source of high impedance. In a CSI fed with a stiff current source, output current waves are not affected by the load. Voltage Source Inverters is one in which the DC source has small or negligible impedance. Other words VSI has stiff DC voltage source and a capacitor parallel across at its input terminals. A CSI does not require any feedback diodes whereas these are required in VSI. The purpose of a DC/AC power inverter is typically to take DC power supplied by a battery, such as a 12-volt car battery, and transform it into a 120 volt AC power source operating at 60 $\mathrm{Hz}$, emulating the power available at an ordinary household electrical outlet.

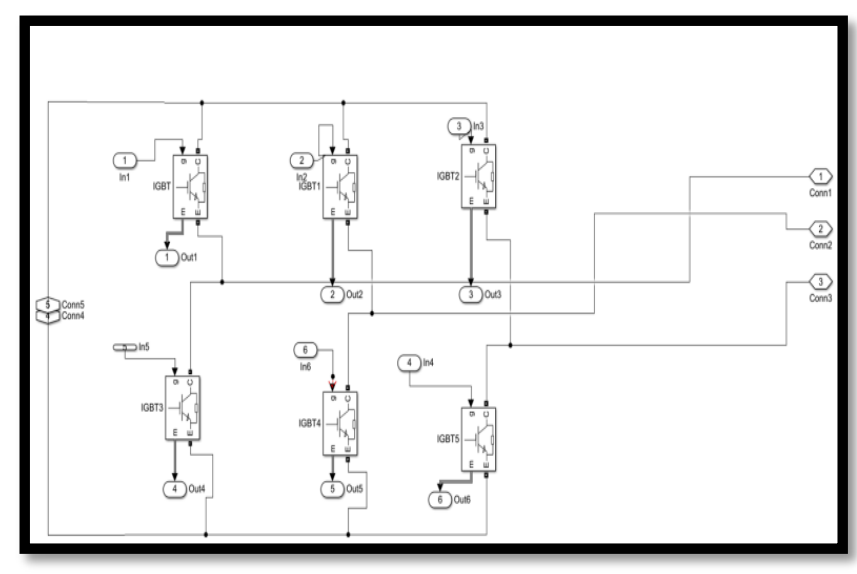

Figure 2: Three Phase Inverter Circuit

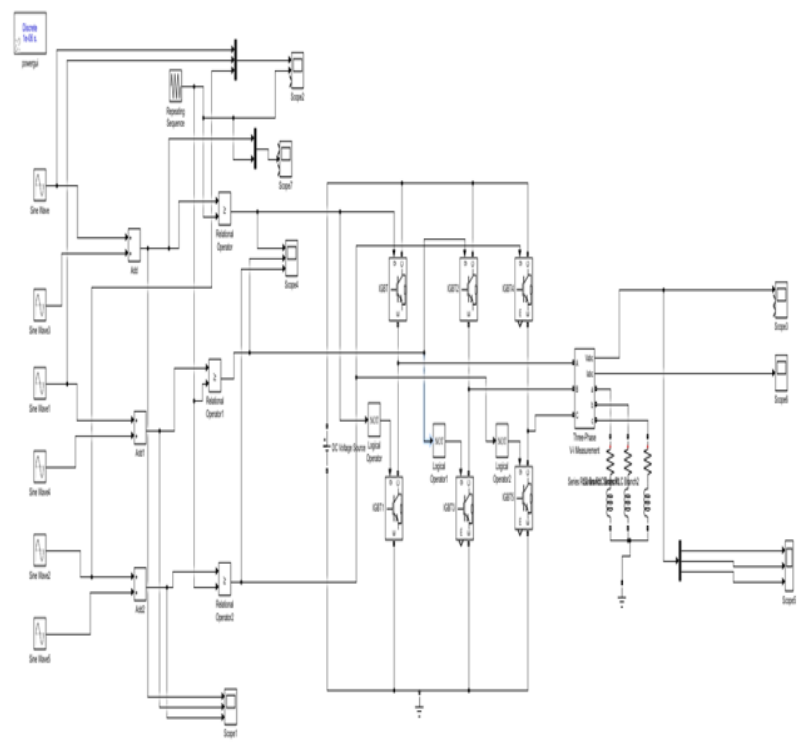

Figure 3: Complete Circuit diagram of THIPWM Inverter

\section{SIMULATION RESULT}

Here we developed a DC to AC inverter in simulation Matlab with a three-phase PWM inverter by controlling the magnitude of voltage and frequency. For controlling the output voltage we use sine pulse width modulation method, in which output voltage is controlled by the modulation index (By changing the modulation index from under modulation to overmodulation). In this paper, we check the effect of modulation

index on the THD (total harmonic distortion) of current/voltage through the FFT of the powerful block which is shown by the different graphs and resulting value's. The Identical magnitudes and phase difference of 120 degrees between them at all operating frequencies. Generating a balanced three-phase sinusoidal waveform of controllable magnitude and frequency is a pretty difficult task for an analogue circuit and hence a mixed analogue and digital circuit is often preferred. Simulation results are obtained using the MATLAB / Simulink environment for the effectiveness of the study. 


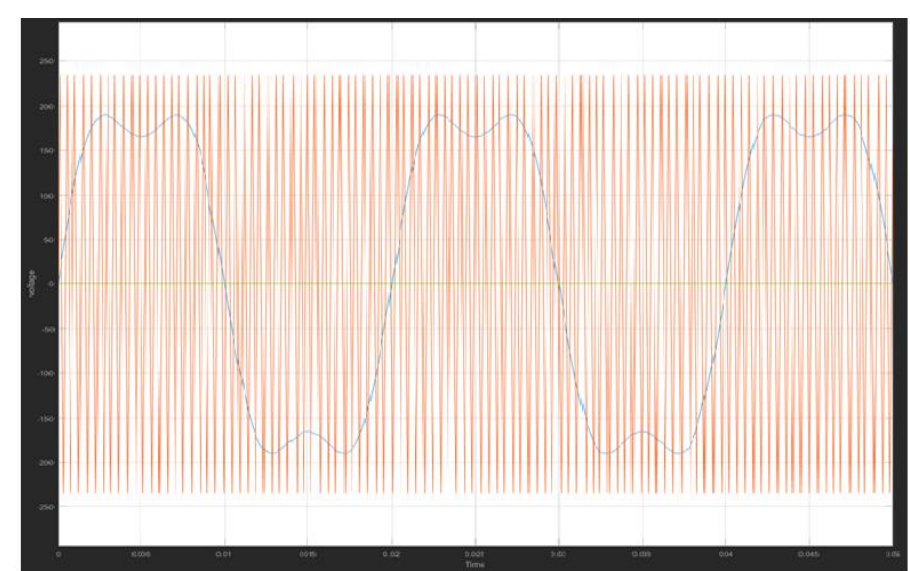

Figure 4: Simulation results obtained for three-phase modulating waveform and phase shifted carrier wave

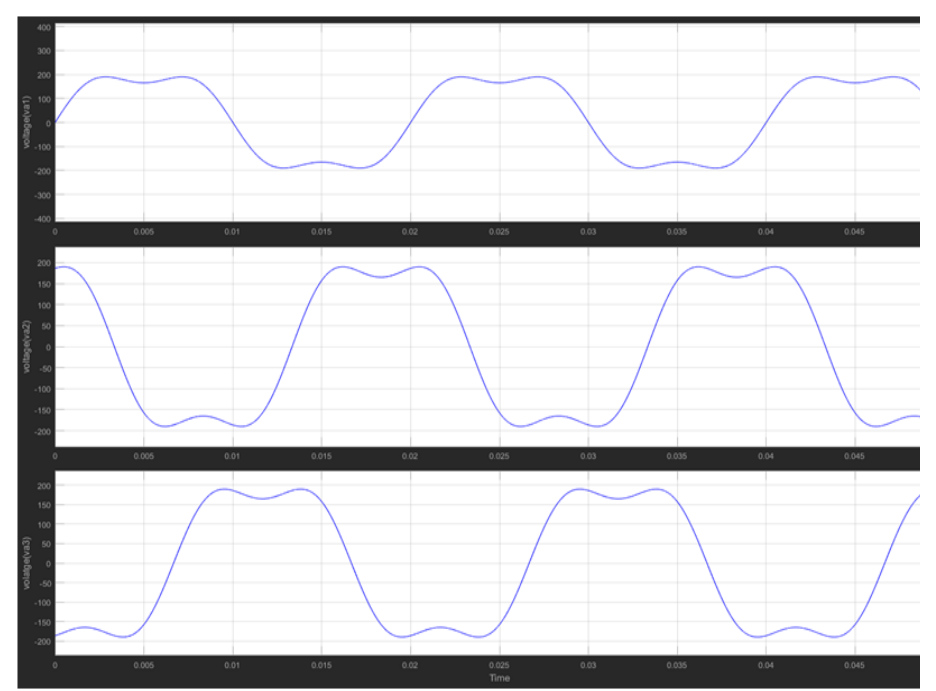

Figure 5 : Simulation results for three phase $3^{\text {rd }}$ harmonic + sine wave

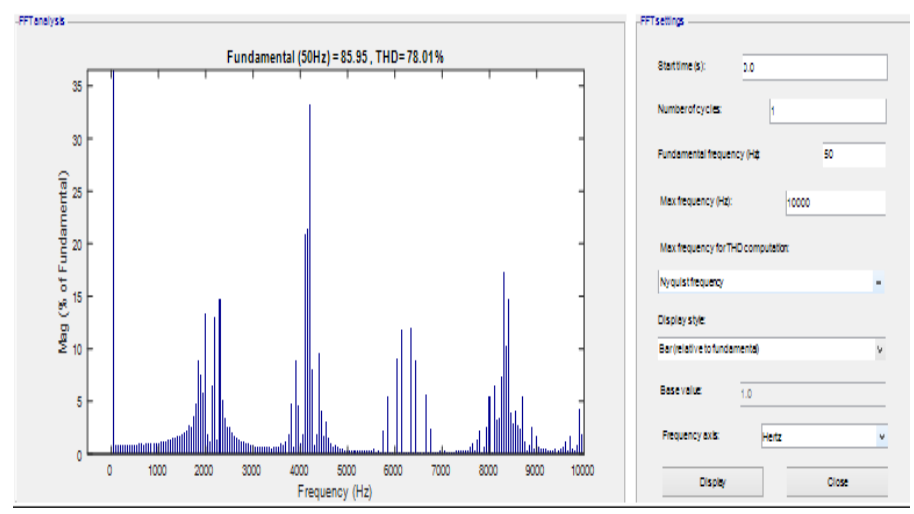

Figure 6 : Harmonic analysis of pwm wave

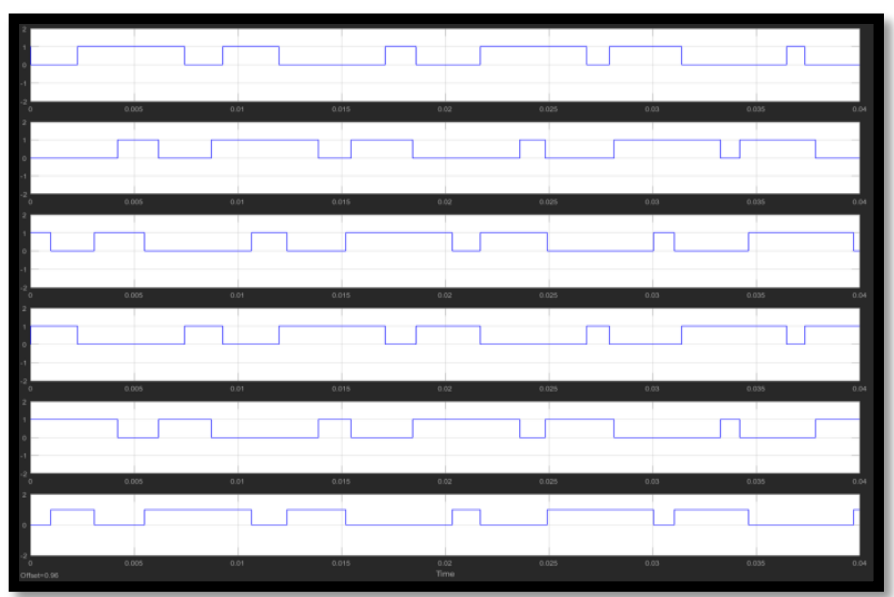

Figure 7: Simulation results obtained Corresponding to Gate Pulse obtained for inverter

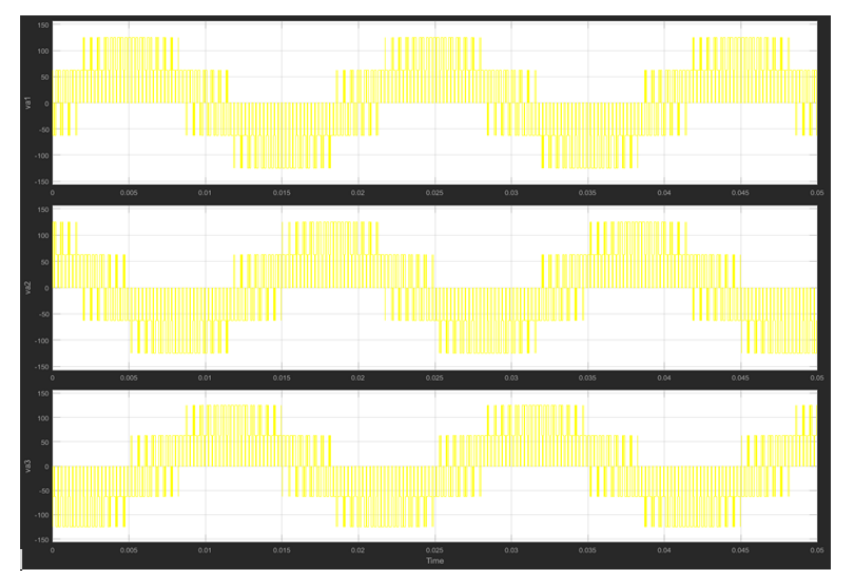

(a)

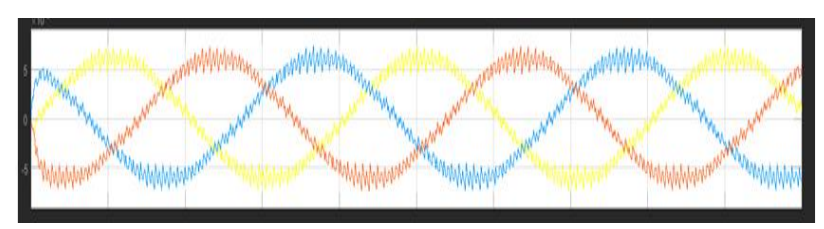

(b)

Figure 7: (a) Voltage with SPWM obtained with R Load in Simulink (b) current obtained with RL load

\section{CONCLUSION}

The main aim of this paper is to reduce the THD of output current/voltage by varying the modulation index between 0.1 to 1. Then we see that we have to fulfil our aim at great extent, mean's that by increasing the modulation index from 0.1 to 1 the value of THD is minimized. The basic drawbacks of the SPWM are not the ideal use of the DC bus voltage and the nonexistent interaction between the three-phase result in a 


\section{Available online at www.ijrat.org}

superfluous change of switching state and also increasing the semiconductor losses.

\section{ACKNOWLEDGMENT}

The Authors would like to thank the reviewers for valuable comments and suggestions and enable us to effectively present our contribution. Authors would also like to thank BBSBEC, Fatehgarh for providing the access to journals and papers required for research work.

\section{REFERENCES}

[1] N. Mohan, U. T. M, and W. P. Robbins, Power Electronics: Converters, Applications and design. John Wiley \& Sons, Inc., 2003.

[2] B. K. Bose, "Power electronics-a technology review," Proc. IEEE, vol. 80, no. 8, pp. 1303-1334, 1992.

[3] J. Holtz, "Pulsewidth modulation--A survey," IEEE Trans. Ind. Electron., vol. 39, no. 5, pp. 410-420, 1992.

[4] J. Holtz, "Pulse Width Modulation for electronic power conversion," IEEE Proc., vol. 82, no. 8, pp. 1194-1214, 1994

[5] N. Mohan, Power Electronics - A first course. Wiley, 2013.

[6] "Control of VSI using spwm strategy for adjustable speed motors." 14th International Research/Expert Conference "Trends in the Development of Machinery and Associated Technology" TMT 2010, Mediterranean Cruise, 11- 18 September 2010.

[7] "Simulation and comparison of spwm and svpwm control for three-phase RL load." IJREAS Volume 2, Issue 2 (February 2012) ISSN: 2249-3905.

[8] Pankaj H Zope, Pravin G.Bhangale, Prashant Sonare ,S. R.Suralkar "Design and Implementation of carrier-based Sinusoidal PWM Inverter." International Journal of Advanced Research in Electrical, Electronics and Instrumentation Engineering. Vol. 1, Issue 4, October 2012

[9] "Performance of Sinusoidal Pulse Width Modulation based Three Phase Inverter." International Conference on Emerging Frontiers in Technology for Rural Area (EFITRA) 2012 Proceedings published in International Journal of Computer Applications® (IJCA).

[10] Muhammad H. Rashid, Power Electronics: Circuits, Devices and Applications(Pearson Education India, 01-Sep-2003)

[11].N. Mohan, T.M. Undeland, W.P. Robbins, Power
Electronics: Converters, Applications, and Design (John Wiley and Sons, Singapore, 1995). 